\title{
Proposta de um modelo de braquiterapia de alta taxa de dose para estudos de radiobiologia in vitro
}

\author{
Jony M. Geraldo ${ }^{1,2,3,4,5}$, Cássia Trindade ${ }^{4}$, Luciana B. Nogueira², Lídia M. Andrade ${ }^{1}$, \\ Clascídia A. Furtado ${ }^{3}$ e Luiz Orlando Ladeira ${ }^{1,3}$ \\ ${ }^{1}$ Nanobiomedical Research Group-Departamento de Física, Universidade Federal de Minas Gerais, Belo \\ Horizonte, Brasil. \\ ${ }^{2}$ Faculdade de Medicina, Universidade Federal de Minas Gerais, Belo Horizonte, Brasil. \\ ${ }^{3}$ Centro de Desenvolvimento da Tecnologia Nuclear, CTDNCNEN, Belo Horizonte, Brasil. \\ ${ }^{4}$ Hospital Luxemburgo, Belo Horizonte, Brasil. \\ ${ }^{5}$ Hospital Alberto Cavalcanti - FHEMIG, Belo Horizonte, Brasil
}

\begin{abstract}
Resumo
O objetivo deste trabalho é desenvolver uma abordagem simples e reprodutível para experimentos de braquiterapia por HDR que permita estudos de irradiação in vitro com base em parâmetros clínicos. Uma plataforma de acrílico foi desenvolvida para manter frascos de cultura de células T25, placas de cultivo múltiplos poços e cateteres de braquiterapia numa posição fixa e rígida durante o processo de irradiação. Imagens tomográficas de todos os arranjos foram tomadas, para em seguida realizar um planejamento 3D com dose de 550cGy no plano das células tumorais aderentes. A fim de medir a dose recebida pelas células, uma dosimetria com filme radiocrômico foi realizada em todos os arranjos celulares. As incertezas relevantes foram levadas em conta. As células tumorais foram irradiadas duas vezes com um intervalo de 24 horas entre as irradiações. Prova da eficácia do modelo proposto foi obtida por análise de efeitos biológicos utilizando uma linhagem celular humana radiorresistente A431 de carcinoma epidermóide. A proliferação celular e a fase do ciclo celular foram avaliadas por ensaio de exclusão de azul de tripan e análise do conteúdo de DNA por citometria de fluxo, respectivamente. Verificou-se que a distribuição espacial de dose obtida é uniforme em todos os frascos e placas de cultura celular, mas há uma incerteza no valor desta dose. No que se refere aos ensaios in vitro, houve uma diminuição da taxa de proliferação celular das células irradiadas com significância estatística $(p<0,05)$. Além disso, um aumento da percentagem de células presas na fase G2 / M (32,3 $\pm 1,5 \%)$ foi observado para o grupo tratado em comparação com células não tratadas.
\end{abstract}

Palavras-chave: braquiterapia, alta taxa de dose, experimentos in vitro, células radiorressistentes

\section{Abstract}

The aim of this research was to develop an easy and reproducible approach for experimental HDR brachytherapy allowing in vitro irradiation studies based on clinical parameters. An acrylic platform was designed to attach T25 tissue culture flasks and multi-well tissue culture plates as well as kept the catheters in a fixed position during irradiation. CT images were taken and the irradiation was planned for 550cGy dose applied on adherent tumor cells. Dosimetric measurements were done and all relevant uncertainties were taken into account in order to figure out the correct dose range received by the cells. Tumor cells were irradiated two times over an interval of $24 \mathrm{~h}$ between irradiations. Proof of concepts of this approach was carried out by biological effects analysis using a radioresistant human epidermoid carcinoma A431 cell line. Cellular proliferation and cell cycle phase were assessed by Trypan blue exclusion assay and DNA content analysis by flow cytometry, respectively. This approach allowed uniform dose distribution around the arrangement in all types of tissue culture plastics evaluated. Corrections due to uncertainties were managed. Regarding in vitro assays there was a significant $(p<0.05)$ decreasing of cellular proliferation rate in irradiated cells. Moreover, increased percentage of cells arrested in $G_{2} / M$ phase $(32.3 \pm 1.5 \%)$ were observed for treated group compared with untreated cells.

Keywords: brachytherapy, high dose rate, in vitro experiments, radioresistant cells

\section{Introdução}

Entre os recurlsos disponíveis para o tratamento de câncer, a braquiterapia é uma modalidade que proporciona alta dose de radiação no volume tumoral e apresenta a vantagem de minimizar a dose nos tecidos sadios vizinhos devido ao decréscimo da dose com a distância em relação à fonte de radiação ${ }^{1}$. Particularmente, a braquiterapia por alta taxa de dose (HDR, high dose rate) tem sido a modalidade preferida, devido à sua capacidade de tratar uma grande variedade de sítios anatômicos, em um relativo curto intervalo de tempo ${ }^{2}$. Embora diferentes fontes de radiação gama estejam disponíveis, o ${ }^{192} \mathrm{Ir}$ é o isótopo mais comumente usado na prática clínica. 
Há vários modelos radiobiológicos para investigar radiorresistência e uma abundância de linhagens de células tumorais que fornecem a maior parte da informação sobre a resposta celular após exposição à radiação ionizante ${ }^{3}$. Sabe-se que alguns eventos celulares estão diretamente relacionados com os esquemas de irradiação, como por exemplo, a alteração do ciclo celular. Após aplicação de radiação ionizante, dependendo do fracionamento da dose, se dose única ou acumulada, impulsionase as células em direção distinta nos perfis do ciclo celular ${ }^{4,5}$.

Alguns modelos radiobiológicos disponíveis para irradiação in vitro de monocamadas de células surgem como uma tentativa de compreender 0 comportamento celular ${ }^{3,6}$. Um deles descreve uma montagem experimental para irradiação in vitro com o objetivo de avaliar resultados radiobiológicos de proliferação celular para esquemas de dose fracionada ${ }^{7}$ Entretanto, estes modelos de irradiação in vitro falham na falta de similaridade com protocolos clínicos empregados na radioterapia ${ }^{5}$. Novos modelos que reproduzem as condições clínicas tanto quanto possível são necessários para que os estudos radiobiológicos forneçam informações que se traduzam em resposta fiel aos esquemas de tratamento atualmente empregados ${ }^{7}$.

Nos últimos anos a indústria tem desenvolvido novas tecnologias para cateter e aplicadores que têm melhorado significativamente a precisão do tratamento, a eficiência e os resultados da braquiterapia ${ }^{8}$. No entanto, a braquiterapia por HDR não se tornou amplamente utilizada para tratamentos de câncer de cabeça e pescoço entre os radioterapeutas, por exemplo, por causa da falta de experiência e de mecanismos radiobiológicos que tem sido mal compreendidos ${ }^{9}$.

Assim, para proporcionar melhorias no conhecimento do comportamento celular sob irradiação de braquiterapia por HDR e utilizando uma modelagem in vitro, propomos uma abordagem inovadora baseada em conceitos clínicos, tais como planejamento $3 \mathrm{D}$ e dose fracionada. Esta abordagem mostrou sucesso, apresentando-se como uma boa configuração para estudos relativos ao impacto da braquiterapia sobre a proliferação celular e alterações no ciclo celular de linhagens de celulas de tumores radiorresistentes. Além disso, garante dose uniforme nas células em estudo, de uma forma simples e fácil de ser reproduzida em qualquer serviço de radioterapia.

\section{Materiais e Métodos}

Para proporcionar uma distribuição de dose uniforme em todas as células tumorais aderentes foi desenvolvida uma plataforma em acrílico (densidade $\rho=1,18 \mathrm{~g} / \mathrm{cm}^{3}$ ), constituída por um empilhamento de três placas com espessura de $10 \mathrm{~mm}$ cada e área de base medindo $156 \times 150 \mathrm{~mm}^{2}$. $\mathrm{Na}$ face da junção das duas placas inferiores há nove cavidades paralelas medindo $2 \mathrm{~mm} \times 120 \mathrm{~mm}$ para fixação de nove agulhas do tipo utilizada em braquiterapia de próstata. A distância entre os centros de cada agulha é de $10 \mathrm{~mm}$. Na terceira placa (superior) há uma fenda para fixação de frascos de cultura celular afim de mantê-los posicionados durante a irradiação. Este arranjo, mostrado na figura 1 , tem como objetivo criar um plano de dose uniforme na posição das células aderentes no fundo dos frascos de cultivo celular.

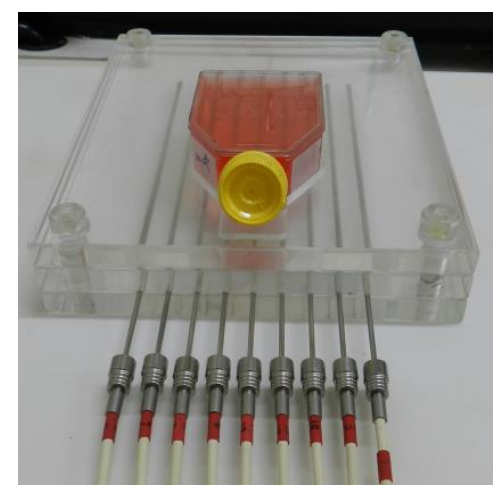

Figura 1. Empilhamento de três placas de acrílico para criar um plano de dose uniforme na posição das células aderentes ao fundo de frascos de cultivo celular. O plano de agulhas está na junção entre as placas inferior e central. O plano de células fica $10 \mathrm{~mm}$ acima do plano das agulhas.

A plataforma acima descrita foi posicionada sobre $5,0 \mathrm{~cm}$ de placas de água sólida (Gammex $457^{\mathrm{TM}}$, Middleton, EUA) e em seguida tomografadas por um tomógrafo modelo Sommaton Siemens (Malvern, EUA). A espessura de cada corte foi mantida entre $1 \mathrm{~mm}$ e $3 \mathrm{~mm}$ dependendo do frasco de cultivo celular tomografado. Esta geometria funciona como um fantoma semi-infinito para melhorar o retroespalhamento ${ }^{10}$. As imagens de TC assim adquiridas foram transferidas para o software de planejamento Oncentra (B 3D versão 4.3 Elekta Inc. (Atlanta, EUA). Os volumes relevantes foram desenhados e os nove cateteres paralelos foram reconstruídos. O passo da fonte foi mantido constante e igual a $5 \mathrm{~mm}$ em todos os cateteres e arranjos. Foi prescrita uma dose de 550cGy por fração. O planejamento foi otimizado utilizando restrições geométricas de modo a gerar uma distribuição de dose uniforme na posição do plano de células aderentes como mostra a figura 2.

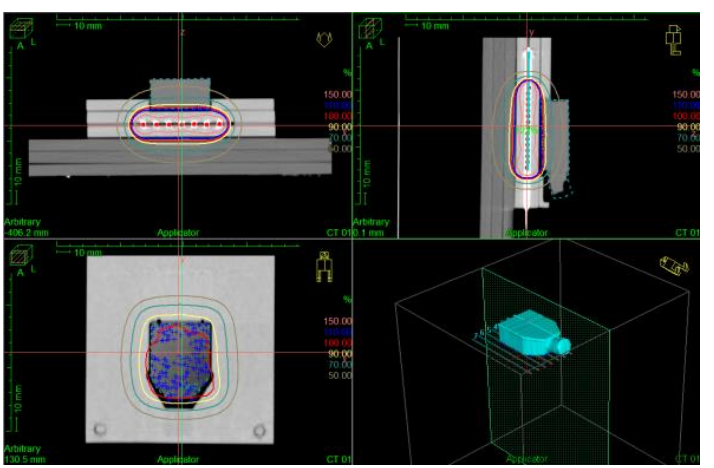

Figura 2. Planejamento da distribuição de dose no software ONCENTRA 3D. As agulhas paralelas produzem um plano de dose na posição das células tumorais. As imagens mostram curvas de isodose que cobrem toda a região onde se localiza o plano de células em um frasco de cultura T25. A curva de $100 \%$ da dose prescrita está representada por linhas na cor vermelha. 
Em seguida foram gerados os tempos e as posições de parada da fonte em cada um dos nove cateteres. Em todos os processos de irradiação (filmes e células) foi empregada uma fonte de ${ }^{192} \mathrm{Ir}$ de um equipamento de braquiterapia por alta taxa de dose fabricado pela Nucletron modelo MicroSelectron® Classic (Utrecht, Holanda).

Para assegurar a dose correta entregue ao plano de células tumorais foi realizada uma dosimetria da fonte de ${ }^{192}$ Ir a fim de se obter a taxa de referência de kerma no ar $K_{R}$. Para a dosimetria utilizou-se um eletrômetro Standard Imaging modelo MAX - 4000 em combinação com uma câmara poço também da Standard Imaging modelo HDR 1000 Plus (Middleton, EUA ). A tensão da câmara foi mantida em + 300V de acordo com o certificado de calibração e escolhida a escala de ' $n A$ ' (nanoAmpere) para medida da taxa de carga.

Como amplamente conhecido, a falta de completo espalhamento (full scatter condition) na plataforma proposta pode levar a incertezas dosimétricas no plano de células de até $13 \%$, como mostrado na dose calculada para as condições de completo espalhamento em comparação com uma de tecido superficial real ${ }^{11}$ e de até $15 \%$, por exemplo, como já foi observado em pontos próximos de uma irradiação superficial de mama ${ }^{12}$. A fim de determinar um fator de correção de dose (FCD) para a plataforma proposta, elaborou-se uma dosimetria com filmes radiocrômicos EBT2 da International Specialty Product (ISP). A geometria empregada para esta dosimetria é mostrada no diagrama da figura 3A. A calibração dos filmes radiocrômicos foi realizada em um fantoma obedecendo à condição de completo espalhamento, obtido substituindo os frascos de cultura de tecidos e sua base acrílica de fixação por cinco placas de água sólida com $1 \mathrm{~cm}$ de espessura cada como mostra a figura 3B.

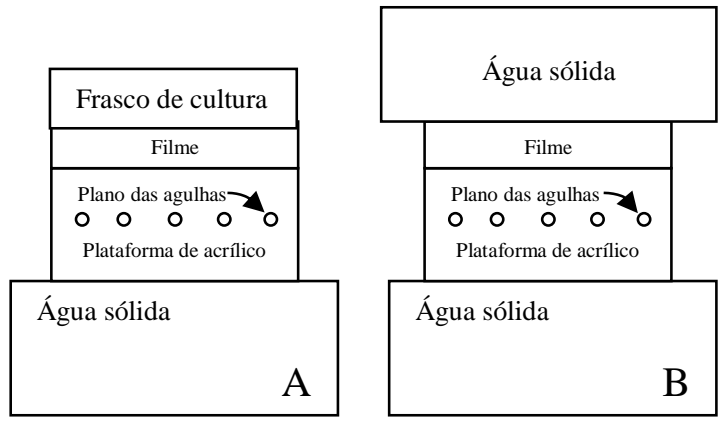

Figura 3. Diagrama esquemático (fora de escala) mostrando em (A) o arranjo para dosimetria dos frascos de cultura celular e em (B) a geometria de espalhamento completo para calibração dos filmes radiocrômicos.

Para a curva de calibração foram dadas as seguintes doses nos filmes: 50, 100, 200, 300, 400, 450, 500, 550 e 600 cGy. Vinte e quatro horas após serem irradiados, os filmes radiocrômicos foram digitalizados em um escaner de transmissão modelo HP Scanjet G4050 (EUA). As imagens digitalizadas foram decompostas em seus componentes RGB usando o software ImageJ $(\mathrm{NIH}$,
EUA ) e os dados obtidos foram analisados pelo software Originlab $\AA$ (Northampton, EUA).

Em todos os experimentos biológicos foi utilizada a linhagem de célula humana radiorresistente A431 de carcinoma epidermóide. As células foram obtidas do ATCC (Manassas, VA), foram crescidas a $37^{\circ} \mathrm{C}$ com $90 \%$ de umidade e atmosfera de $5 \%$ de $\mathrm{CO}_{2}$. Foram incubadas em DMEM contendo $1 \mathrm{mM}$ de piruvato de sodium da Gibco (Grand Island, NY), suplementado com $5 \%$ de FBS da LGC Biotechnology (Cotia, SP, Brasil). O corante Trypan Blue foi obtido da Gibco (Grand Island, NY) e o iodeto de propídio da Invitrogen (Mariland, USA). Os frascos T25 e as placas multi-poços foram obtidas da Kasvi (Curitiba, PR, Brasil) e TPP (Switzerland). Todos os outros reagentes foram da mais alta qualidade comercialmente disponíveis.

Vinte e quatro horas antes da irradiação $6 \times 10^{5}$ células A431 foram semeadas em um frasco de cultura e $5 \times 10^{4}$ células foram plaqueadas em uma placa de 24 poços. Para irradiação, os frascos de cultura foram colocados em seu local na plataforma de acrílico e as nove agulhas de aço conectadas aos seus respectivos canais no indexer do equipamento de braquiterapia através de tubos de transferência como mostra a figura 4. Em todas as irradiações foi planejada e prescrita uma dose de 550 cGy por fração. As células foram irradiadas duas vezes por semana à temperatura ambiente. Os frascos foram irradiados na mesma posição em todos os experimentos e, após receber a dose programada, eles retornaram para a incubadora na atmosfera de $\mathrm{CO}_{2}$ onde foram mantidos até retornarem para uma segunda fração de dose.

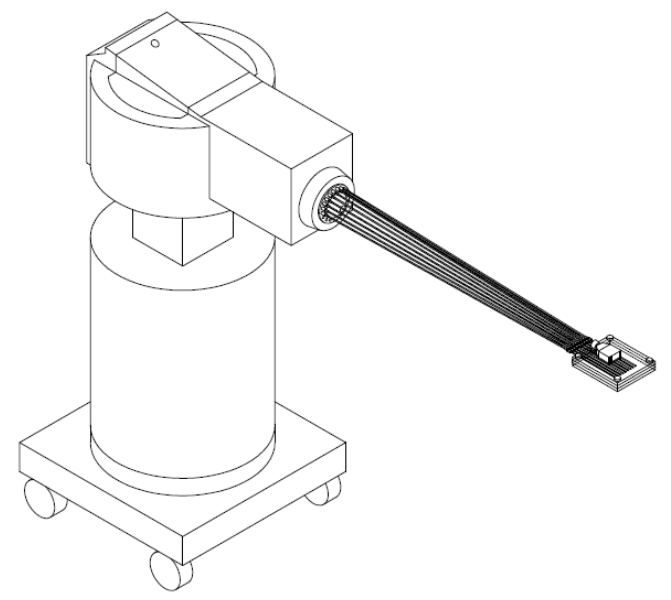

Figura 4. Representação esquemática da irradiação in vitro por braquiterapia. A imagem mostra um frasco T25 fixado em sua fenda na plataforma de acrílico. Os frascos de cultura de células foram mantidas no centro da plataforma. Cada agulha foi conectada ao aparelho de braquiterapia por um tubo de transferência para passagem da fonte de ${ }^{192} \mathrm{Ir}$.

Procedimentos para ensaios de proliferação celular foram previamente descritos ${ }^{9}$. Os resultados estão expressos como médias e desvios padrões. Para avaliar a significância estatística o método por correlação $t$ Test foi empregado e, em todos os casos, um valor de $\mathrm{p}<0,05$ foi considerado como indicando significância estatística. 


\section{Resultados}

Com base em parâmetros clínicos para a braquiterapia, obtidos a partir de planejamento tridimensional, nossos resultados mostraram distribuição de dose desejável em todo o plano de células aderentes tanto semeadas em frascos T25 quanto semeadas em frascos de cultura multipoços. As células aderentes cresceram na parte inferior dos frascos de cultura de tecidos, onde $100 \%$ da dose havia sido prescrita. Regiões possíveis de sub irradiação celular foram evitadas devido à inserção de dois cateteres para além das bordas exteriores dos frascos de cultura de tecido como mostrado na figura 2.

Nossa plataforma de braquiterapia se encaixa em experimentos in vitro para estudos radiobiológicos porque permite o uso de diferentes tipos de frascos de cultura de tecidos. Os frascos foram mantidos na mesma posição durante o processo de irradiação, eliminando incertezas quanto ao posicionamento das células em relação à fonte de radiação, o que contribui para evitar a ocorrência de células sub dosadas.

Na medida da taxa de referência do kerma no ar $K_{R}$, após a obtenção da máxima leitura $L_{m}$ do eletrômetro e aplicação das correções relevantes, $K_{R}$ foi obtida através do formalismo recomendado ${ }^{13}$. Em seguida a atividade da fonte foi obtida por meio dos processos usuais ${ }^{14}$ e comparada ao valor da atividade do certificado de calibração da fonte, corrigido para tempo de decaimento pela equação de costume. Os valores são coincidentes com diferença percentual de $1,4 \%$.

À medida que os planejamentos de tratamento por braquiterapia por alta taxa de dose tornam-se mais complexos, é cada vez mais importante ter-se meios de verificar a otimização dos resultados ${ }^{15}$. Com base nisso, foi realizada uma dosimetria com filmes radiocrômicos para avaliar as incertezas quanto à dose planejada e a dose recebida pelas células irradiadas em cada um dos frascos de cultivo celular. A geometria das medidas dosimétricas e da calibração dos filmes radiocrômicos é mostrada no diagrama da figura 3 .

Apesar de que uma isodose planar tenha sido obtida na posição dos filmes, uma análise mais acurada mostra que a dose real recebida foi diferente daquela prevista devido à forte dependência da dose com a distância. Uma incerteza de $1 \mathrm{~mm}$ na posição do filme conduz a correção na dose de $\pm 3 \%$. Corrigir a posição do filme no planejamento para irradiação dos frascos de cultura celular nos permitiu uma melhor avaliação da dose recebida pelos filmes radiocrômicos. Além disso, cada filme foi escaneado três vezes para obter o erro associado ao processo de digitalização utilizado para obter os componentes RGB. A média da densidade óptica assim obtida foi associada com a dose no filme de calibração. As incertezas foram calculadas e o resultado é mostrado na tabela 1.
Tabela 1. Doses planejadas, doses corrigidas e incertezas na irradiação dos filmes radiocrômicos para obtenção da curva de calibração.

\begin{tabular}{cccc}
$\begin{array}{c}\text { Dose } \\
\text { planejada } \\
\text { (cGy) }\end{array}$ & $\begin{array}{c}\text { Dose corrigida } \\
\text { na posição do } \\
\text { filme (cGy) }\end{array}$ & Densidade óptica & $\begin{array}{c}\text { Incerteza } \\
(\%)\end{array}$ \\
\hline 50 & 53 & $0,0376 \pm 0,0062$ & 1.6 \\
100 & 106 & $0,0788 \pm 0,0063$ & 0.8 \\
200 & 212 & $0,1266 \pm 0,0062$ & 0.5 \\
400 & 424 & $0.1953 \pm 0,0072$ & 3.7 \\
450 & 477 & $0,2178 \pm 0,0068$ & 3.1 \\
500 & 530 & $0,2416 \pm 0,0101$ & 4.2 \\
550 & 583 & $0,2586 \pm 0,0101$ & 3.9 \\
600 & 636 & $0,2816 \pm 0,0123$ & 4.4 \\
\hline
\end{tabular}

Com base nos dados da tabela 1 foi traçada a curva de calibração de dose versus densidade óptica como mostra a figura 5. Ajustando uma equação polinomial de segundo grau sobre os dados encontra-se a seguinte expressão:

$D=B_{0}+B_{1}(D O)+B_{2}(D O)^{2}$

onde $D$ é a dose em unidades de cGy, DO é a densidade óptica dos filmes irradiados e $\mathrm{B}_{0}, \mathrm{~B}_{1} \mathrm{e}$

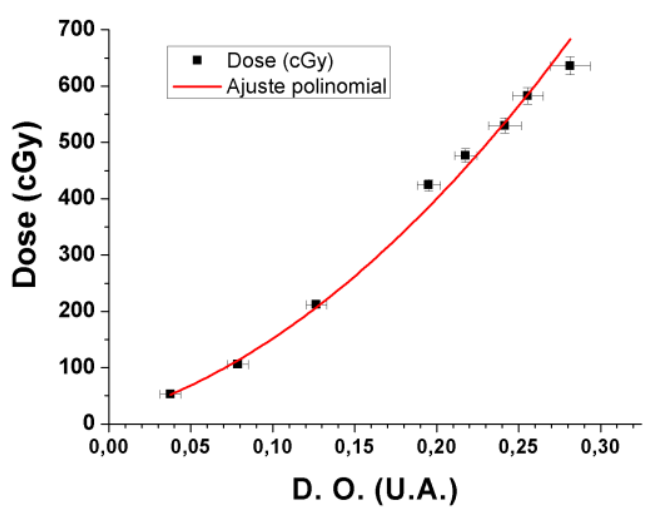

Figura 5. curva de calibração obtida por um ajuste polinomial de segundo grau com os dados da Tabela 1.

$B_{2}$ são parâmetros obtidos no processo de ajuste (coeficiente de correlação $r^{2}=0,993$ ) com os seguintes valores: $12450 \pm 3826,848,045 \pm 95,659$ e $5450,907 \pm 376,518$, respectivamente.

Aplicando a mesma estratégia, as densidades ópticas dos filmes irradiados para cada frasco de cultura celular foram obtidas e o resultado é mostrado na tabela 2. Os dados mostram que a dose absorvida pelas células é diferente das doses planejadas. Faz-se necessário definir um fator de correção de dose (FCD) como sendo a razão entre a dose medida $D_{\text {meas }}$ e a dose planejada $D_{\text {plan }}$ de acordo com a seguinte relação:

$F C D=\frac{D_{\text {meas }}}{D_{\text {plan }}}$

Para todos os frascos de cultura a dose planejada foi de 550cGy e usando a Eq. (2) o valor de FCD foi calculado conforme descrito na Tabela 2. 
Tabela 2. Fator de correção de dose (FCD).

\begin{tabular}{|c|c|c|c|}
\hline Arranjo & $\begin{array}{l}\text { Densidade óptica } \\
\text { média }\end{array}$ & $\begin{array}{c}\text { Dose média } \\
\text { (cGy) }\end{array}$ & FCD \\
\hline $\begin{array}{l}\text { Fantoma de } \\
\text { referência }\end{array}$ & $0.2476 \pm 0.0078$ & $557.1 \pm 27.9$ & 1.013 \\
\hline Frasco T25 & $0.2474 \pm 0.0096$ & $556.9 \pm 34.1$ & 1.012 \\
\hline $\begin{array}{l}\text { Placa de } 6 \\
\text { poços }\end{array}$ & $0.2443 \pm 0.0042$ & $545.0 \pm 14.8$ & 0.991 \\
\hline $\begin{array}{l}\text { Placa de } 24 \\
\text { poços }\end{array}$ & $0.2427 \pm 0.0050$ & $539.6 \pm 17.7$ & 0.981 \\
\hline $\begin{array}{l}\text { Placa de } 96 \\
\text { poços }\end{array}$ & $0.2343 \pm 0.0061$ & $510.7 \pm 20.9$ & 0.927 \\
\hline
\end{tabular}

Em resumo, se uma dose Dplan é prescrita no sistema de planejamento para aplicações in vitro utilizando o modelo proposto, a dose recebida pelas células $\mathrm{D}_{\text {cell }}$ pode ser obtida pela relação:

$D_{\text {cell }}=F C D \cdot D_{\text {plan }}$

Quanto aos resultados biológicos, a Tabela 3 mostra que houve uma redução na proliferação celular de $46,8 \% \pm 2,3 \%$, com os dados normalizados pelo controle. Isto sugere que 0 modelo de braquiterapia proposto é eficiente para reduzir a proliferação de células tumorais em cultivo usando um número reduzido de frações.

\begin{tabular}{ccc}
\multicolumn{3}{c}{ Tabela 3. Taxa de proliferação celular após a braquiterapia } \\
\hline Tempo (dias) & Controle & Irradiado \\
\hline 0 & $50,0 \pm 0,0$ & $50,0 \pm 0,0$ \\
1 & $312,5 \pm 65,4$ & $227,1 \pm 81,8$ \\
2 & $433,3 \pm 26,3$ & $206,3 \pm 4,2$ \\
3 & $654,2 \pm 123,9$ & $191,7 \pm 2,8$ \\
4 & $877,1 \pm 104,4$ & $118,8 \pm 12,9$ \\
\hline
\end{tabular}

Quando o ciclo celular foi avaliado, os resultados mostraram que nas células irradiadas houve parada do ciclo celular na fase $\mathrm{G}_{2} / \mathrm{M}(4 \mathrm{~N})$ de $32,3 \pm 1,5 \%$, comparado com as células controle que foi $8,22 \% \pm$ $1,2 \%$ como mostrado na figura 6 .

\section{Discussão}

Os desafios enfrentados pela radiobiologia em braquiterapia encontram-se numa melhor compreensão dos efeitos em tecidos normais e no volume alvo, resultantes da exposição às taxas de dose utilizadas que variam largamente ${ }^{16}$. Um bom ponto de partida para alcançar o conhecimento dos efeitos biológicos sobre células cancerosas irradiadas é o desenvolvimento de uma boa modelagem de braquiterapia como um verdadeiro tratamento planejado para os pacientes, o que propusemos nesta investigação. Nossos resultados demonstram uma distribuição de dose praticamente uniforme em frascos de cultura de tecidos, atingindo todas as células tumorais aderentes, evitando assim regiões de sub irradiação.

Muitas incertezas foram evitadas pela plataforma proposta, uma vez que ela é capaz de manter os frascos de cultura celular em posição fixa em relação à fonte de radiação. Atenção deve ser dada para o planejamento do tratamento objetivando assegurar a posição correta do plano de células que deve ser considerado como um PTV a ser desenhado e tratado.

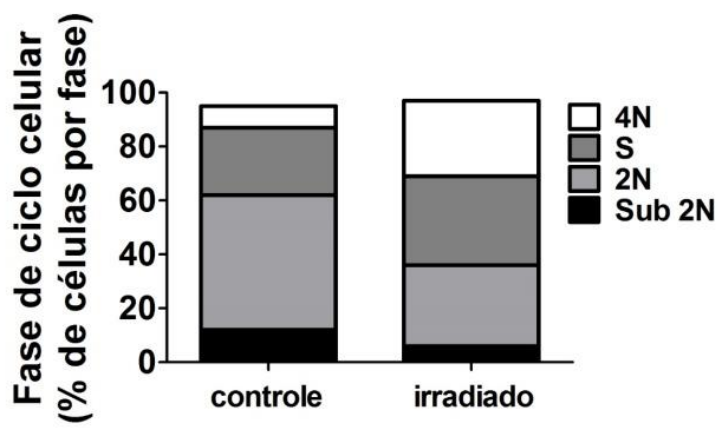

Figura 6. Avaliação do ciclo celular das células irradiadas e do grupo controle. Os resultados mostram que houve uma acentuada parada do ciclo celular na fase $\mathrm{G}_{2} / \mathrm{M}(4 \mathrm{~N})$ para as células irradiadas quando comparado com as células do grupo controle.

O processo de digitalização dos filmes pode conduzir a um desvio de até $4,4 \%$ no valor da densidade óptica, com reflexo na dose medida no plano de células.

Considerando que 0 arranjo proposto não assegura uma condição de completo espalhamento para o conjunto de células, fez-se necessária a proposição de um fantoma de referência que tem a geometria ideal para avaliar a dose recebida no plano celular. Espera-se que medidas dosimétricas neste fantoma gerem doses médias tão perto quanto possível da dose planejada. Em vez disso, obteve-se um valor médio de 557cGy, isto é 1,3\% maior do que a dose prevista de 550cGy como mostra os dado da tabela 2. Certamente isso se deve à placa de acrílico de $1 \mathrm{~cm}$ de espessura entre a fonte e o filme em nosso fantoma de referência. Pode-se dizer que a presença desta placa de acrílico impõe um acréscimo na dose de 1,3\%, um valor próximo aos apontados na literatura ${ }^{17}$.

Uma vez que a placa de acrílico sobre as agulhas está presente em todas as modalidades, deve-se esperar o mesmo fator de correção para a dose em todos os arranjos de cultivo celular devido à presença desta placa de acrílico. Portanto, os diferentes valores de FCD observados na tabela 2 são devidos à contribuição de dois fenômenos: a falta de completo espalhamento da plataforma proposta e à placa de acrílico presente no arranjo entre a fonte de radiação e o plano de células. É possível avaliar isoladamente a contribuição da falta de espalhamento total tendo em mente que as diferentes doses observados na tabela 2 são devido a estas duas contribuições.

Como pode ser visto, devido à falta de espalhamento completo no arranjo de células, a dose recebida pelas células é menor do que a dose planejada. Um frasco T25 quase garante espalhamento total ao plano de células. Na pior situação (placa de 96 poços), a falta de espalhamento total contribui com o maior fator de correção de dose, um valor próximo a 7,2\%. Uma placa de 96 poços tem quase metade de seu volume preenchido com meio de cultura celular e a 
outra metade cheia de ar e, assim, a redução da dose é quase metade do que é observado na prática clínica $^{14}$.

\section{Conclusões}

A plataforma proposta garante uma posição fixa rígida de ambos: a placa de células e o trajeto da fonte de radiação. As nove agulhas paralelas servem como um dispositivo para uma fonte de ${ }^{192} \mathrm{Ir}$ gerar uma superfície de isodose uniforme na posição do plano de células aderentes. Apesar de fortes recomendações para se ter $20 \mathrm{~cm}$ de água para proporcionar uma condição de espalhamento total, as experiências de dosimetria deste trabalho mostram que uma camada de três centímetros é suficiente para estabelecer esta condição. Esta conclusão é válida pelo menos para a energia dos raios gama da fonte de ${ }^{192} \mathrm{Ir}$, cuja energia é baixa quando comparada com as altas energias empregadas em tratamentos de teleterapia. Os resultados mostram uma boa correlação com os apontados na literatura, uma vez que na prática clínica $5 \mathrm{~cm}$ de água são suficientes para uma condição de total espalhamento para feixes de teleterapia de até $6 \mathrm{MeV}$ de energia.

Os resultados biológicos mostram que o modelo de braquiterapia proposto é eficiente para reduzir a proliferação de células tumorais em cultivo, posto que houve uma redução na proliferação celular de $46,8 \% \pm 2,3 \%$, com os dados normalizados pelo controle. Avaliação do ciclo celular mostrou que nas células irradiadas houve parada na fase $\mathrm{G}_{2} / \mathrm{M}(4 \mathrm{~N})$ de $32,3 \pm 1,5 \%$, comparado com as células controle que foi $8,22 \% \pm 1,2 \%$.

\section{Agradecimentos}

Gostaríamos de agradecer ao Eduardo A. Barcelos pela usinagem da plataforma de acrílico e ao Kennedy B. Gonçalves por suas contribuições. Agradecemos a todo corpo clínico do Instituto de Radioterapia São Francisco e do Hospital Luxemburgo por fornecer a estrutura para o planejamento e irradiações de braquiterapia e à plataforma de Citometria de Fluxo do Instituto de Ciências Biológicas-UFMG. Agradecemos também às agências brasileiras de fomento FAPEMIG (grant number BPD-00022-14), CAPES-PNPD e CNPq (grant number 402610/2013-0) pelo suporte financeiro.

\section{Referências}

1. Jefrey F. Willimson, David J. Brenner. Physics and Biology of Brachytherapy. Principles and Practice of Radiation Oncology, $5^{\text {th }}$ edition, Halperin, E. C., Perez, C A and Brady, L W. Lippincott Willimas\& Wilkins, 2008, 423-475.

2. Subir Nag, Granger, R Scruggs, Clincal Aspects and Applications of High Dose Rate Brachytherapy. Principles and Practice of Radiation Oncology, $5^{\text {th }}$ edition, Halperin, E. C., Perez, C A and Brady, L W. Lippincott Willimas\& Wilkins, 2008, 560-582.

3. Hall EJ, Giaccia AJ. Radiobiology for the Radiologists. McAllister L, editor. 6th, 5-521. 2006. Philadelphia, Lippincott Williams \& Wilkins

4. Powathil GG, Adamson DJ, Chaplain MA. Towards predicting the response of a solid tumour to chemotherapy and radiotherapy treatments: clinical insights from a computational model. PLoS.Comput.Biol. 9[7], e1003120. 2013.
5. Andrade LM, Geraldo JM, Gonçalves OX, Leite MTT, Catarina AM, Guimarães MM et al. Nucleoplasmic Calcium Buffering Sensitizes Human Squamous Cell Carcinoma to Anticancer Therapy. J Cancer SciTher 4[5], 131-139. 25-5-2012.

6. Andrade LM, Campos TPR, Leite MF, Goes AM. In vitro response of the human breast cancer cell line MDAMB-231 and human peripheral blood mononuclear cells exposed to $60 \mathrm{Co}$ at single fraction. Brazilian Archives of Biology and Technology 48[2], 205-213. 24-10-2005

7. Tesei A, Sarnelli A, Arienti C, Menghi E, Medri L, Gabucci E et al. In vitro irradiation system for radiobiological experiments. Radiat.Oncol. 8[1], 257. 1-11-2013.

8. Cancer Manag Res. 2015; 7: 199-211. Published online $2015 \mathrm{Jul}$ 16. doi: $10.2147 / C M A R . S 46042$ PMCID: PMC4507789. Review of advanced catheter technologies in radiation oncology brachytherapy procedures Jun Zhou, Leonid Zamdborg, and Evelyn Sebastian

9. J Radiat Res. 2013 Jan; 54(1): 1-17. Published online 2012 Nov 23. doi: 10.1093/jr/rrs103 PMCID: PMC3534285 High dose rate brachytherapy for oral cancer Hideya Yamazakl, Ken Yoshida, Yasuo Yoshioka, Kimishige Shimizutani, Souhei Furukawa, Masahiko Koizumi, and Kazuhiko Ogawa.

10. Dose Calculation for Photon-Emitting Brachytherapy Sources with Average Energy Higher than $50 \mathrm{keV}$. Full Report of the AAPM and ESTRO. Report 229 (2012)

11. S. Raina, J. S. Avadhani, M. Oh, H. K. Malhotra, W. Jaggernauth, M. R. Kuettel, and M. B. Podgorsak. "Quantifying IOHDR brachytherapy underdosage resulting from an incomplete scatter environment." Int JRadiatOncolBiol Phys 61(5):1582-1586 (2005).

12. J. A. Raffi, S. D. Davis, C. G. Hammer, J. A. Micka, K. A. Kunugi, J. E. Musgrove, et. all. "Determination of exit skin dose for 192lr intracavitary accelerated partial breastirradiation with thermoluminescent dosimeters." Med Phys 37(6):2693-2702 (2010).

13. Nath R., Anderson L. L., Luxton G., Weaver K. A., Williamson J. F., Meigooni A. S. Dosimetry of interstitial brachytherapy sources: Recommendations of the AAPM Radiation Therapy Committee Task Group No. 43; Medical Physics 22, 209-234 (1995).

14. M.A. Gadhi, S.A. Buzdar, M. Afzal, Sh. Fatmi, M.S. Akhtar, A.H. Nizamani. Calibration of iridium-192 source by ionization chamber for high dose rate brachytherapy. Int. J. Radiat. Res., 11(3): 189-193 (2013).

15. Quality assurance for high dose rate brachytherapy treatment planning optimization: using a simple optimization to verify a complex optimization Christopher L Deufel and Keith M Furutani. Published 17 January 2014 - 2014 Institute of Physics and Engineering in Medicine Physics in Medicine and Biology, Volume 59, Number 3

16. Recent developments and best practice in brachytherapy treatment planning C D LEE, MSc, MIPEM Physics Department, Clatterbridge Cancer Centre, Bebington, Wirral, UK. Br J Radiol. September 2014; 87(1041): 20140146. Published online 2014 Jul 23. doi: $10.1259 /$ bjr.20140146

17. Absorbed Dose Determination in External Beam Radiotherapy. TECHNICAL REPORTS SERIES No. 398. International Atomic Energy Agency, Vienna, 2000.

Contato:

Jony Marques Geraldo

Hospital Luxemburgo - Rua dos Gentios 1350

Luxemburgo - Belo Horizonte - MG

E-mail: (jony.marques@mariopenna.org.br) 